\title{
From West to East: British Sojourners' Acculturation in China
}

\begin{abstract}
Purpose: Previous literature has often focused on Asian migrants' acculturation to Western cultures with data collected in the Western contexts. This study will explore Western consumers' acculturation to East Asian cultures and their consumption behaviour, which fulfils the research scarcity in this area.
\end{abstract}

Design/methodology/approach: This study was conducted via carrying out in-depth interviews with 18 British sojourners in China, exploring how they acculturated to Chinese culture, with a particular focus on their food and media consumption choices. This study applied inductive qualitative data analysis to build on but explore beyond existing theory.

Findings: The findings show that British consumers display a diversified acculturation strategy towards different products. They present an integrative approach to food consumption with a negotiable identity to host culture value whilst they adopt a separated approach relating to traditional media consumption, showing a non-negotiable consumption stance. They apply an assimilated approach for pragmatic reasons in terms of social media adoption.

Originality/value: British sojourners in China hold a different cultural stance in different areas of consumption. The study contributes to existing theory by arguing the complexity of a continuous negotiation process between different value systems in sojourning consumers' consumption choices, which existing acculturation models have not yet examined. By emphasising the context speciality, the findings give marketers clear marketing implications when targeting sojourning consumers who declare their value stance via consumption practice.

Key words: Acculturation, Sojourner, Food consumption, Media Consumption, British value, Chinese value 


\section{Introduction}

With the increasing global mobility via fast and different transportations, the convenience of travelling provides more opportunities for people to sojourn in another country/region. Travelling between an individual's home country and host country has become easier and more frequent since the start of globalisation (Bardhi et al., 2012). Whilst there is still a fast growth of the Eastern population sojourning or immigrating to Western countries, particularly to those traditional immigrate countries such as Canada, Australia, New Zealand and the United States, there is also a continuous increase of people from the West, coming to countries in the East, such as Thailand, Vietnam and China.

Taking China as an example, a growing number of Westerners have travelled to China over the years, leading to a population of over 980,000 foreigners living in China in 2015 ( $\mathrm{Li}$, 2017). Foreign sojourners often come to China for reasons such as education, work, family union or volunteering on a short-term basis; only very few foreigners come to China with the intention of obtaining Chinese citizenship, due to China's immigration policy restriction (Lu, 2013). The increasing number of sojourners in China, on one hand, represents a growing market, and on the other hand presents opportunities and challenges to marketers, businesses and brands. Though the West-to-East geographic mobility phenomenon is gaining popularity, it has attracted limited research attention, particularly in terms of consumption.

"Sojourners" refers to people who engage in temporary between-society contact. Different from tourists, sojourners typically live in a country for a longer period of time, e.g. between six months to five years (Hottola, 2004). Their travel usually has specific and goal-oriented purposes such as education or work. Sojourners are inclined to adjust to local cultural norms to some extent and are characterised with openness, flexibility and tolerance (Gudykunst, 2004). Dissimilar to immigrants, sojourners tend to have a clear home orientation (Yen et al., 2018) and as a result, they present a more complex cultural identity, as their sojourn is only 
temporary and their home cultural identity needs to be maintained to a degree, ready for them when they return home.

When travelling to a new country, consumers engage in an acculturation process wherein they learn and make sense of the new cultural norms and values from the host country, whilst maintaining their home country cultural identity (Cleveland \& Laroche, 2007). Extant acculturation studies emphasise the consumers' negotiation of their home versus host cultural identity via consumption and possession (Bardhi et al., 2012), and assume that consumers' consumption choices can be predicted and explained based on their acculturation outcomes during travel (Cleveland et al., 2011). Some point out that such acculturation outcomes are fluid (Penaloza, 1994), rather than originally conceptualised as suggested by Berry (2008), depending on the situation of consumption (e.g. He \& Wang, 2015; Edirisingha et al., 2015), and result in some forms of cultural swapping (Oswald, 1999).

Nevertheless, the majority of acculturation studies and frameworks are often derived based on immigrants' acculturation to the West. It is unclear whether such frameworks could be applied to effectively explain and predict Western consumers' acculturation to the East. Although some attempts have been made by scholars, such as Thompson and Tambyah (1999), Ward and Rana-Deuba (2000) and Bardhi et al. (2010) to discuss acculturation in Eastern contexts, their works have some limitations, for example, the usage of a heterogeneous sample, including both Western and Eastern respondents (Thompson and Tambyah, 1999; Ward and Rana-Deuba, 2000), and the use of travellers rather than immigrants or sojourners (Bardhi et al., 2010). Such scant research attention leaves it a challenge to marketers, brands and policy makers to understand or target these Western sojourning consumers through effective marketing decisions. 
In response to the academic silence, this study aims to explore how British sojourners acculturate to modern day Chinese culture. Choosing China as the host culture is of particular interest due to its closed-door policy during the Cultural Revolution from the 1960s to 1970s, which hindered its cultural interactions with "Others", though historically China was inclusive with a great number of ethnic minority cultures. China also represents a strong unified host culture, which is dominated by the Han Culture within the country. The study selected British sojourners as the sample to ensure sample homogeneity. The number of British sojourners in China makes it one of the largest Western sojourning groups (Li, 2017). Also, British culture represents a strong composition in modern Western culture, due to the initiation of the industrial revolution from the $17^{\text {th }}$ to $19^{\text {th }}$ centuries and its colonialisation (Harris and Zucker, 2018), wherein British explorers, travellers and priests set foot onto every continent in the world and spread its political, legal, linguistic and cultural legacy (Evans, 2011).

This study investigates the sojourner's acculturation with a particular focus on studying their food and media consumption choices and practices via eighteen in-depth interviews. Food and media are chosen for observation for two main reasons. First, food culture and media culture in China have unique and strong host culture imprints throughout Chinese history. They reflect the Chinese philosophies and are distinctively different from the Western (and British) alternatives. Second, food and media provide convenient platforms for participants to identify, label and reflect their consumption choices (e.g. home, host and others) during everyday life in China. Other consumption categories such as transport and clothing are also explored; however, as our British participants feel these categories are less affected by the cultural difference when travelling to China, they cannot therefore be used to fully illustrate their acculturation in China over the years. 
Using inductive qualitative analysis, we use theoretical concepts on acculturation, food and media consumption as sensitising lenses to interpret findings (see Silverman, 2013). Findings reveal that British sojourners display a variety of culturally inconsistent consumption choices to satisfy their various needs and demands, suggesting a pragmatic view to acculturation. For example, whilst they apply a very integrative approach to food choices, consuming a variety of food alternatives, they adopt a very different cultural stance in media consumption choices. For social media choice, they are quite localised by using Chinese social media Apps for pragmatic reasons. However, they demonstrate a separation strategy in terms of traditional media consumption, as they reject news produced by the Chinese statecontrolled media for their lack of debate, information freedom and variety. We argue that the pick and mix of various consumption choices by British sojourners in China reveals an acculturation strategy that is pragmatic in its approach. This pragmatic approach provides British sojourners with a solution to maintain a harmonious and congruent cultural identity, demonstrating fluidity in their cultural stance during their sojourn in China.

The findings are of significance to marketers, brands and people who are keen to serve sojourning and travelling consumers, as it shows that consumers' consumption and product choices can be fluid, not only across different acculturation outcomes (Askegaard et al., 2005), but also across different areas of consumption. This extends previous understanding in acculturation that assumes that identity outcomes influence consumption practices in the same way, regardless of the field of practice. Instead, dissimilar consumption choices are enacted to reflect and declare their various cultural stances in different fields of practice pragmatically, giving implications to consider better marketing for sojourning consumers in different host cultures.

\section{Literature Review}


Acculturation is understood as "the process in which individuals learn and adopt the norms and values of a culture different than the one in which they grew up" (Cleveland \& Laroche, 2007: 250). In studying the degree of an individual's negotiation between the host and home cultures, unidimensional and bi-dimensional acculturation models represent two key research strands. Whilst a unidimensional approach to acculturation argues that the change of an individual's identity is measured on a continuum ranging from home culture to host culture (Ryder et al., 2000), the bi-dimensional acculturation model proposes a four-pattern acculturation strategy, comprising assimilation, integration, separation and marginalisation, based on the balance towards the composition of levels of home and/or host culture (Berry, 1997; Berry, 2008). Although being highly influential in the studies of migration across many disciplines, Berry's (2008) conceptual model of acculturation has been recently criticised for proving a rigid and inflexible conceptualisation of migrants' identity (Yu et al., 2018).

Empirical studies have shown that migrants' identity can be more fluid than originally conceptualised by Berry (2008) when they adapt to the challenges of a new cultural context. For example, Mexican immigrants in the US consume American objects (e.g. clothes and cars) in public settings, showing their integration with the US culture, while in domestic settings their consumption of food and media remain Mexican with a purpose of maintaining their ethnic identity (Penaloza, 1994). Similarly, other studies show how immigrants adapt their food choices depending on the situation of consumption (e.g. He \& Wang, 2015; Edirisingha et al., 2015). Edirisingha et al. (2015: 490) show how Sri Lankan consumers in England or New Zealand negotiate their collective family identity through meal consumption, performing a "malleable and fluid family identity: one in their social sphere among friends and the other within the extended family."

Furthermore, Oswald (1999) observes how immigrants continuously swap between ethnic and host cultures depending on the consumption occasions. They do not adopt a single 
acculturation outcome, since they "play out their ethnicity individually, depending on day-today encounters with the host culture" (Oswald, 1999: 311). Indeed, their identity is a process in which, for example, "rather than gradually erase the difference in the interests of assimilation, Haitian Americans navigate an uneven path between both worlds, culture swapping as they go" (Oswald, 1999: 315). In criticising Oswald for having neglected the role of global consumer culture (GCC) in their study, Askegaard et al. (2005) show its influential role in generating a new acculturation outcome, namely the pendulum, describing immigrants that oscillate between various cultures. Pendulum "involves maintenance and assimilation, but the term stresses the oscillation and the consequent existential problems connected to persistent biculturalism" (Askegaard et al., 2005: 167).

Existing studies provide an overview of migrants from the East to West countries but does not provide much information about migrants vice versa. Thompson and Tambyah (1999), Ward and Rana-Deuba (2000) and Bardhi et al. (2010) are the few exceptions. Thompson and Tambyah (1999) studied the cultural adaptability among fourteen expatriates in Singapore through their consumption and leisure practices. They argued that when the self was threatened by the abundance of unfamiliar cultural cues at a foreign destination, food became an anchor that reminded the travellers of who they really were and was a way of reestablishing familiarity and daily routines. However, among these fourteen respondents, three of them were from Eastern countries/regions, i.e. Hong Kong, Malaysia and India, and two of them were of Eastern origin, i.e. Korea and Cambodia. Hence, they could not illustrate a full picture of Western migrants to the East. Similarly, Ward and Rana-Deuba (2000) conducted a quantitative study to investigate the psychological adjustment of sojourners in Nepal using 104 respondents from different nationalities including both Western (e.g. Canada, Switzerland, Germany, Denmark, British, American) and Eastern (e.g. Japan, Singapore, the Philippines). Bardhi et al. (2010) conducted a qualitative study exploring a group of 
American consumers' food consumption during their 10 days travelling in China. Their findings revealed different food perceptions when participants travel across national boundaries; however, the duration of the travel is too short to observe consumers' acculturation but more of a reflection of consumers' cultural shock and their coping mechanism. Since the context of migration is crucial to understand how people acculturate to the new environment (Ulver \& Ostberg, 2014), there is a need to better understand how consumers from one homogenised Western culture acculturate to Eastern contexts (Willis \& Yeoh, 2002).

Fundamentally different from immigrants, sojourners are often more home orientated (Bardhi et al., 2012). People who sojourn in another country may demonstrate a different pattern to host culture acculturation, as sojourners have less motivation to settle down in the host country forever (Sui, 1952). With the ultimate purpose of leaving the place, sojourners tend to view themselves as outsiders to the community and have potential in demonstrating a more transformative identity, meshing work and tourism during their sojourn (Yen et al., 2018). Whilst one type of sojourner, such as expats, have set tasks to complete in a specific time, the length of time people sojourn in the host country may vary depending on individual situations in terms of motivation, experience, prestige, security, etc. (Ward \& Rana-Deuba, 2000).

Moreover, sojourners are also very different from tourists, who usually spend a very limited amount of time in the host country before going home. Compared to tourists, who may simply go for familiar brands to sustain their daily consumption rituals back home (Bengtsson et al., 2010), sojourners are more motivated to adapt to the local values, social norms and consumption practices in the host country (Ward \& Rana-Deuba, 2000). Furthermore, sojourners who spend most of their time in one host country are also different from global 'nomads' who continue to move from place to place, characterised by frequent 
short-term international travels (Bardhi et al., 2012). Global nomads demonstrate a more detached and flexible consumption pattern, focusing on the products' situational as well as functional values.

\section{Acculturation: Food and media}

Previous studies on acculturation have highlighted the crucial roles that food and media play in the everyday life of migrants who want to keep alive their cultural identities but also integrate into a new cultural context (Penaloza, 1994). Adapting one's diet to the new cultural environment has been described as one of the most problematic aspects of migration since it causes anxiety and worry (Cappellini \& Yen, 2013). The introduction of new ingredients and products in migrants' diet is seen as a sign of integration to the new host culture. The introduction of new brands and dishes in ordinary meals reveals the complex cultural negotiation that migrants undertake in navigating a new marketplace with the aim of reshaping their food habits away from home. If ordinary meals are reshaped over time, extraordinary ones including family gatherings and celebrations, seem to be more static as they are considered a way of keeping alive familial bonds and cultural identity (Penaloza, 1994).

As we know very little about British sojourners and their consumption practices, we can only speculate that they might maintain some of their culinary habits developed at home, which include an open appetite for foreign cuisines. In fact, British consumers exhibit a diet in which new and exotic brands are frequently introduced into their ordinary meals (Warde et al., 1999). This is indeed the case of middle-class consumers, whose consumption of exotic products at home and outside has been explained as a result of their high social and cultural capital (Cappellini et al., 2016). 
Existing research also uses media as a strong indicator to examine immigrants or sojourners' acculturation process (Yang et al., 2004). Current research strongly supports the predictive assumption of media use to the degree of acculturation to a new social environment (Wilkin et al., 2009). Media offers immigrants a route for cultural contact that avoids the uncertainty and anxiety that often accompany interpersonal interactions in the early phases of adaptation (Kim, 2001). Host mass media provides sojourners with a variety of cultural elements and cues that aid in their comprehension of the new culture's history, values and current issues (Yu et al., 2018). Research findings suggest that host media allows immigrants and sojourners from the East to learn the ideologies or values of the host culture, thus facilitating the acculturation process (Raman \& Harwood, 2016).

Consumption of host mass media (for example television, magazines, radio, newspapers and the Internet) has been seen as an accelerator of the acculturation process (Khan, 1992). In fact, television has been used by immigrants as a learning device, helping them to familiarise themselves with new cultural values and a new language (Dalisay, 2012). Since host mass media is used as a learning space to understand values and replicate certain behaviours, it has been suggested that it facilitates a smoother and faster integration (Woo \& Dominick, 2001). Conversely, if migrants do not engage with host mass media, but continue consuming mass media from their home countries, their acculturation process will be negatively affected (Raman \& Harwood, 2016).

With the easiness of internet access and online social network adoption, social media has been considered crucial in promoting acculturation with the host environment but also maintaining a pre-acculturation identity (Raman \& Harwood, 2016). Studies looking at media and acculturation highlight how engaging in social media promotes interaction amongst peers and amongst consumers and organisations, overcoming the geographical obstacles of time and space (Cappellini \& Yen, 2016). In providing a space for creating, developing and 
sustaining social and cultural relationships in the home and host contexts, empirical studies on social networks have shown how they serve as coping platforms for mitigating complexities and solving tensions arising during the initial stage of arrival (WamwaraMbugua et al., 2008). Social media becomes a learning space in which the new cultural environment is discussed, and new consumption practices are deciphered, negotiated and often adopted (Yu et al., 2018). Considering these empirical findings, we argue the importance of studying social media as a strong force which drives the development of collective identities amongst immigrants in their acculturation process.

\section{Food culture in China}

Scholars of food-related behaviour have been keenly aware of this noteworthy relationship between believing and eating, and between eating and belonging (Wu \& Cheung, 2002). China is a country heavily reliant on agriculture, which makes food particularly important for the people. Chinese food culture can be dated back as early as the Shang Dynasty (from 1600-1046 B.C.). The sentence "The People are the most important to an Emperor, while food is the most important to the People" in the book titled Historical Records in the Western Han Dynasty (206 B.C.-9 A.D.) reflected the great importance of food in Chinese people's daily life. The profound Chinese food culture has always been emphasised in its preparation, presentation and ways of consumption. The complication and prosperity of food culture reached its peak during the Tang and Song Dynasty, which was described as overly exquisite (Zhao, 2012).

Chinese food is deep-rooted in and reflects Chinese cultural values and philosophies. In particular, the concept of "Ying and Yang", which stems from Taoist philosophy, is embedded in Chinese traditional medicine from martial arts to food. The Ying and Yang concept emphasises the balance of two opposites but complements elements in the universe, such as 
the balance of flavours, temperature, colour, ingredients, nutrition and cooking techniques in authentic Chinese food.

Such an emphasis on balance also reflects harmonious human relations in Chinese society, conveying Chinese cultural values and philosophical views. Serving special and rare food can be used to show respect and hospitality to guests or friends. Dining out and sharing food may indicate a close relationship (Ma, 2015). Food is also specially prepared to celebrate important events or festivals, such as mooncakes for Mid-autumn festival, and dumplings (Jiaozi) for Chinese New Year. Many kinds of food are recalled as metaphors to give wishes and blessings to others for different occasions. For example, eating noodles for a birthday celebration leads to good health and longevity. Putting peanuts and dates in a newly wedded couple's bed blesses them to be able to conceive a baby easily and early.

Unlike Western society, where food culture is highly related to religion, Chinese foodrelated behaviour seems relatively innocent of taboos and prohibitions $(\mathrm{Wu}$ and Cheung, 2002). Many Westerners feel shocked by Chinese cuisine because it is so open, and so unfettered by particular taboos, that snake, jellyfish or chicken feet may turn up in a meal. When Western food companies enter China's consumer market, they often adapt to Chinese food culture. For example, McDonald's China Eatery used the unconventional 10-person round table in the restaurant, with a slogan "It's good to get together" as a way of accommodating the traditional Chinese relational culture (Wang et al., 2000; Wang \& Mowen, 1997).

\section{Media culture in China}

Controlling the consumption of media has always been considered as an effective way to control people's ideology (Stockmann \& Gallagher, 2011). This has been reflected frequently in Chinese history when a new authority has come to power. The earliest example recorded in 
Chinese history was "the burning of books and burying of scholars" in 212 B.C. by the first Chinese emperor Qin Shi Huang. This marked the end of the glorious period in Chinese history when there existed "a hundred schools of thoughts", during which people could express their own ideas and speak freely. When Mongolians established the Yuan Dynasty in China (1271-1368 A.D.), they started their governance by slaughtering the literati and applied a slavery governing system using ethnic minorities who were illiterate or knew nothing in Chinese. There was tough censorship on arts, plays and literature to prevent the Han Chinese from expressing their political resentment. A similar history was repeated when the Manchus conquered the Ming Dynasty in 1644 A.D. In order to establish its authority as a 'barbarian' government, the imperial court tried very hard to suppress and censor original intellectual creativity from the previous dynasty by controlling the media (Ren, 2011).

In modern Chinese history, the state tightly controlled all outlets for media, restricting not only their numbers but also their content, length and format during the Chairman Mao era (1949-1976). The Cultural Revolution represents its peak in terms of suppressing intellectuals and hard censorship on media contents. Raids on families, searching for forbidden books, were carried out and people who had a 'false' speech could be reported and detained in prison (1966-1976). During that period, Chinese people were controlled by what they could read, listen, watch or talk about. Control of information was close to total (Hassid, 2008). Media control has changed since the reform in the late 1970s with the development of marketisation. The number of news providers and the range of acceptable content have both dramatically increased (Hassid, 2008). However, no matter how the latest technology has changed the number, format and content of media, the control and censorship by the government are still very tight (Xin, 2010; Stockmann \& Gallagher, 2011).

\section{Methodology}


This study used qualitative research that identified themes from the informants' descriptions of their own experience in terms of food and media consumption. We recruited British citizens living in China through personal referrals of the researchers. All the respondents were sojourning in China or had just relocated back to the UK within 3 months since their last entry to China. Fifty British sojourners were approached by different contacts including 15 females and 35 males. Altogether 18 respondents agreed to participate in the study and were interviewed and all of them were males apart from one female (see Table 1).

\section{[INSERT TABLE 1 HERE]}

The interviews were conducted either face-to-face or by using an internet communication App (e.g. Skype or WeChat) by two of the authors who can speak fluent English and Mandarin, depending on participants' preference. Three interviews were conducted in person and the rest were carried out by Skype or WeChat. The interviews were mainly conducted in English, with additional Chinese phrases to explain certain Chinese dishes and/or phenomena that are specific to the Chinese context. The average interview lasted approximately one hour in length. Interviews were recorded under participants' consent and then later transcribed into text documents and analysed thematically (Spiggle, 1994).

Following McCracken's (1988) guidelines, interviews were started with general questions, such as personal background, profession and the motivation to visit China initially. After that, questions were focused on each respondent's daily food consumption and normal media consumption. Guided by literature review, we then followed the typical open coding process of inductive qualitative analysis, which emphasises the researchers' effort of seeking to add or discard dimensions to sensitising concepts with on-going data analysis (Silverman, 2013).

\section{Findings}

Food consumption 
In mapping participants' patterns of food consumption during the period of their stay, two main categories emerged, namely ordinary (often associated with their consumption during the week) and extraordinary food consumption (mainly during weekends and on special celebratory occasions). In addition, five consumption options are discussed (see Table 2).

\section{[INSERT TABLE 2 HERE]}

\section{$\underline{\text { Home-cooked Food }}$}

Considering the convenience of getting takeaway food or ordering food at restaurants in China, home cooking is generally minimised by most of the participants, apart from those living with young children, as families tend to cook and consume more home-made food. Often participants cook Western food one day and then Chinese food the next, or maybe a Chinese breakfast, followed by a Western lunch/dinner or the other way around, showing a variety of integrated consumption choices. Interestingly, the choice is categorised as between Chinese and Western, rather than between Chinese and British food. When asked specifically whether their food creation at home is going to be British, participants often felt that their home-cooking was generic Western, not particularly British per se. For example,

"I do a lot of cooking at home ... Not typical British food, more Western food, I'd say. I think British food is kind of awful. But I think as what you grow up or grow up eating, this is always a little bit part of you. You always kind of miss it..." (Participant Tim)

"I cooked for my Chinese friends. But because of the limited resources that we have in the kitchen, I've only cooked pasta. So it's not actually British food, but...it is also kind of British food... this is the food that I grew up with..." (Participant Colin)

Whilst participants often alternated between the familiar Western food and easily accessible Chinese food in their home cooking, food consumption was inevitably a negotiation for those in a mixed-race family. For example, participant Chris explained: 
"Although breakfast is more or less fixed on the Western side for me...actually my [Chinese] wife has Chinese breakfast. ... She is trying to encourage our daughter to have a different breakfast every day. So she (daughter) sometimes has Weetabix, sometimes she has Chinese porridge. ... Interestingly enough, when we go out, (just the two of us), it is inevitably just Western meal. That is what we associate with going out for eating."

Chris' comment not only reveals the daily negotiation practised by British sojourners in mixed-race families, but also highlights the craving for home food that is often experienced by migrants and sojourners during their travels (Cappellini et al., 2019). This may be because home food offers the comfort, security, familiarity and satisfaction that is wanted by people during their everyday navigation in foreign countries, even though for the British sojourners in China, home food could be somehow replaced by Western food in principal. For instance, Participant Tom commented:

"I try to have a balance of Chinese and Western food... one Chinese, one Western... I don't like to eat too much Western food. I don't like people come to China and don't eat Chinese food. ... I only have Western food one meal a day maximum. Sometimes, when I am very hungry, I crave something like a big pizza or steak. .... I think Western food makes me feel more stuffy, more meat."

Whilst home food is strongly associated with a sense of security and comfort and consumed for safety, familiarity, reassurance and maintenance when travelling abroad (Yen et al., 2018), our findings suggest that often British sojourners are not highly attached to home food but are very happy to sample and experience host cultural food for different occasions.

\section{$\underline{\text { Western restaurants }}$}


Our findings show that Western restaurants and bars were mostly consumed in by participants on special occasions. Different from Western restaurants, Western bars in China are considered adult only and different from British pubs at home. Yet they offer a comforting space for expats to gather and enjoy other Westerners' company, such as French, Germans, Americans, Australians, etc. Participant Ben explained:

"There is a bar that caters for the expats. They do it well. I might have some fries, some spaghetti Bolognese. I might go out with a Chinese friend for as well. ... It is a popular place. You'd have some locals, but most popular with the expats."

Despite their popularity amongst Western expats, not every participant shares the same positive feeling for such Western bars in China.

"We go to the bars where most Westerners go. To be honest, the Westerners here are a bit peculiar. I think there is a lot of really strange Western people coming here. I don't know they are coming here to find girlfriends, or to get some easy work or something. Some of them are just very questionable." (Participant Arnold)

Western-styled restaurants, which are priced more expensively than Chinese restaurants in general, were consumed in for different reasons by participants who might feel "too lazy to cook" (Participant Tom) or who are "missing home a little" (Participant Charlie). English menus and Western cutlery provide the convenience and comfort that was required by participants after a long day at work. For instance, participant Ted said:

"It is heartened to see that many places of eating or even the canteens are having the menus in English, so I can go there and point to something. ... having people speaking English at these places helps me out. ...Before, if you go to Yummy's [a local restaurant, serving both Chinese and Westerns food], no one speaks English. ... Now, there are some canteens people speak English, it is great..." 
For mixed-race families, Western-styled restaurants are consumed in for comfort and for passing on the British-home identity to the next generations. For example, Participant Chris said:

“When we go out as a family, we'd take our daughter to a Western restaurant... Maybe once a month... We'd always like to have soup at the beginning, then salad, and probably a fish dish. Always a dessert- we love to have a big dessert. We don't have it too often, but we like it... something like apple pies... Probably in Italian restaurants, they normally serve that kind of food."

\section{$\underline{\text { Chinese restaurants }}$}

Our findings show that for the majority of our participants, Chinese food was consumed on a regular daily basis and formed the main part of their diet. This is very different from previous studies of Chinese sojourners in the UK - rather than cling onto their home food or seek a substitute from global food brands, host food is very much consumed and often enjoyed by British sojourners in China. For example, Participant Charlie commented:

“We eat probably 70\% Chinese food on the day-to-day base. I love xiaolongbao 小笼包 (mini steamed buns), roubao 肉包(meat buns), we like those simple, street food. They are just very convenient when you are outside. I like huoguo 火锅(hotpot). Many different kinds of dishes in Chinese restaurants, like tangculiji 糖醋里脊 (sweet \& sour tenderloin, niangao 年耪hard rice cake), shuizhuroupian 水都肉片 (meat slice in boiling water) all sorts of dishes. Chinese food is so much different, so much variety and they are from different regions."

Participant Colin also said:

"I like to try to find out the local specialities during my travel. So when I was in Chongqing, Chengdu I went to have hotpots. ... In places like Shanghai, I had Xiaolongbao (small steamed buns). In Lanzhou, I had Lanzhou lamian (noodles). ... and the Chinese people are good at 
finding those things. There is a really brilliant App that all the Chinese young people used called Qunaer (去哪么) which not only gives you hostel listings but also find local specialties for food and different places in the local places ..."

Our findings show that Chinese restaurant food was consumed by participants in various ways. For the majority of our participants, the Chinese restaurants' food was generally affordable and offered a satisfactory taste. They could be consumed in on a regular basis as a family eating out option, a gathering place with colleagues after work or a more celebratory choice for special occasions, such as festivals or special banquets.

\section{Chinese fast food}

In addition to Chinese restaurants, the convenience offered by street food vendors and the variety of food was applauded by some participants.

"My normal breakfast would be the one like the pancake with egg, spicy and they kind of roll it up, very greasy but I like that. You can hold it in a bag and you can have it on a go. No one minds. I think if it is in the UK, you see someone like that holding a plastic bag in the metro, you have to be tolerated. I like the grab and go culture here. There are too many instances you have to sit down and take 20 minutes in the UK." (Participant Edward)

In comparison to Participant Edward who was very keen on Chinese food and demonstrated an in-depth knowledge of different Chinese dishes and street food options, most other participants tended to stick to their Western food for breakfast, before venturing out for Chinese street food for lunch or dinner for its easy accessibility, convenience and taste.

Global fast food brands 
Our findings show that global fast food brands such as McDonald's, Pizza Hut, Starbucks, etc. are not regarded favourably by participants, contradictory to previous studies of American travellers in China (Bengtsson et al., 2010). They are occasionally consumed for convenience and sometimes for their resemblance of Western home food. For example, Participant Charlie commented:

"I go for McDonald's because I sometimes miss the Western food, but mostly because of its convenience. McDonald's, KFC, Pizza Hut, they operate 24 hours and 7 days. But Chinese restaurants don't deliver 24 hours."

Apart from their convenience, global fast food brands are very much criticised for their premium pricing, their unhealthy food and their aggressive marketing, intrusive to the Chinese cultural environment. Participants tended to hold a very critical view in discussing global brands in China and refused to take refuge in the familiar servicescape provided by global brands. For example:

“....but pizza hut here is completely different to pizza hut in England. I find it makes me laugh a little bit. Pizza Hut in England is cheap and you eat it quickly and escape. If you go to Pizza Hut in China, it is like you go to a semi-luxurious restaurant. I never ever experienced this in my life and people have business lunch at Pizza Hut. It was like 'really? Pizza Hut?" (Participant Arnold)

"You go around the west lake which is a symbol of Hangzhou, a symbol of China, UNESCO world heritage, there is just Starbucks, everywhere. In the last year, particularly I noticed the amount of Starbucks opening up. .... It is this one thing that I really don't like. It is the fusion between the West and the East, the aggressive marketing and places like Starbucks, and fads like things confine cakes. " (Participant Andy).

\section{Media Consumption}


When asked about media consumption, the Chinese government's media censorship was immediately acknowledged. Participants held a critical but pragmatic view of the Chinese firewall and the state media's lack of freedom of speech. For instance, Participant Jake stated:

"Things I dislike about China? ...The pollution, the traffic, schools, freedom of the press, freedom of the internet. You cannot really see movies that you want to watch. You cannot buy the book you want to read, you cannot go on the website you want to visit... But you just get a VPN so actually, you can."

Whilst the censorship was "annoying and frustrating" (Participant Edward), all the participants had managed to obtain a VPN (virtual private network) app and/or device to overcome the firewall and gain some access to familiar mass media such as the BBC and Guardian and social media, for example, Facebook, Instagram and WhatsApp. Table 3 illustrates three different types of media that are consumed for various values.

\section{[INSERT TABLE 3 HERE]}

\section{$\underline{\text { News }}$}

In terms of news consumption, British media was regarded as the preferred choice, especially for obtaining international news that was not censored by the Chinese government. On the other hand, Chinese news media was followed for a very specific purpose, to better understand what was happening in China or to practise Chinese. However, since Chinese media is state-controlled, it is not judged as a suitable channel for international news for its lack of debate and the solitary way of portraying the rest of the world. Participants explained:

"If I am on the computer. I read the Guardian. If I am on the phone, I read the BBC. I use a VPN here. For the written news, the media is exclusively English...Chinese media is statecontrolled.” (Participant Wilson). 
"I don't really like the Chinese state media so I don't follow the Chinese TV news. I know news is news and it is not always true, but I think maybe the Chinese news is worse than others. .... I find the Chinese state media always has a big agenda and say what they want to say. If something happens, everybody suddenly hates British people, or suddenly don't like French people if something happens... Some people can be easily influenced and become passionate about it and I think it could be very dangerous." (Participant Tom)

"Chinese news is very sterilised. There is no real debate or discussion. There is no time for people to have a proper debate. It is either to be blunt or aggressive or relaxed and calm. There is no politician introduced on the programme... You just never hear any debate." (Participant Ted)

\section{Entertainment}

In comparison to the news, participants held a less critical view of Chinese entertainment. Chinese movies and TV soap operas were consumed sometimes for their entertainment values and practising their Chinese. For example,

"I watched a lot more TV, it was mainly movies on the TV. So we have HBO and we have Star movies, which also have Chinese movies. I do like Hong Kongnese movies - I think they are excellent." (Participant Chris)

"There is a latest movie called 'A touch of sin'. Have you watched that? 'Black coal and thin eye'? which is very good. I think it is quite an exciting time now for China with all modern films. I think it is really good for the Chinese people as they can watch films that are of really good quality, not just like Hollywood blockbuster films... There are some good classical ones, like Red Sorghum, Crouching Tiger, hidden dragon." (Participant Tim)

Whilst Chinese state-controlled news was criticised for its lack of variety in its debate, participants demonstrated a much more positive attitude towards Chinese media 
entertainment and regarded it as a constructive counterforce to Hollywood dominance. Nevertheless, this does not mean that Western entertainment is dismissed. Often, Western movie channels and popular TV series were skilfully accessed, avoiding the detection of the firewall and then consumed for comfort, familiarity and popularity. For example:

"My Chinese listening and speaking are ok. I watched the Chinese TV a little bit. But if I am out the whole day, speaking Chinese, I would like to switch my brain off. I watch something English...It is easier to have something that I don't have to think about." (Participant Tom)

"I tried the VPN. ...In a day I remembered that I had enough of finding everything is so difficult to get things done, I just stayed at the hostel and using VPN and watched a comedy show. Once you are in China, you are in China, it is fully immersive." (Participant Paul)

“Mainly, I watch TV series, like HBO TV series, the latest stuff but my wife like some of the TV series as well, like Game of Thrones. We watch together. We just download them. A lot of Chinese people get hold of them so we can." (Participant Tim).

\section{Social Media}

Whilst many of the familiar Western social media platforms are banned and therefore unpopular with Chinese users, Chinese social media is very much embraced by our participants on a daily basis for convenience and networking opportunities in China. Apps such as WeChat was mentioned as essential to get by in China. For example, Participant Colin illustrated:

"Everyone uses WeChat in China. When we arrived in China, we all download WeChat to use. Everyone who is Chinese told me to download it... It is very convenient and useful."

"Everyone I know here in China uses WeChat. I can use Facebook to message my friends back home but using VPN.... All my family members have WeChat because I made them get 
for me. They are a little bit frustrated because there are so many messaging apps... But they are quite happy to have WeChat..." (Participant Emma)

However, although WeChat provides easy access to remain connected to families back home via video talks, instant messaging, photo sharing, etc., participants often struggled to persuade all their families, friends and social network contacts to relocate their existing social network onto WeChat for reasons such as consumer inertia or loyalty (White and Yanamandram, 2004). As a result, to remain connected with existing social networks back home, VPN was constantly used to provide access to the banned Western social media, such as Facebook, Instagram, WhatsApp and Skype. Participant Charlie commented:

"No, I don't use WeChat to communicate with my friends and family members in the UK, we use Facebook, WhatsApp. Although I did get a couple of my friends onto WeChat, that's because they are coming to visit us in China. Now they go back to England, they don't really use it any more. They just have their own thing in England."

Similar frustration was shared by Participant Jake:

"I use Instagram sometimes via VPN. The thing is that all our Western friends and family are not using WeChat. There is no way. Most friends use WhatsApp and I communicate with my Western friends and WeChat for Chinese friends. Just my parents downloaded WeChat."

"I still use Facebook or Instagram to communicate with my friends back home.

... I do want to know what is going on back home. ... I would say I am on pretty often because sometimes, I got free time so I just scroll through and have a look at things. ... For everyone here, I use WeChat. I often use WeChat but I don't often use Facebook unless there is something big, for example, if I went to Beijing. I was really exciting, so I put on pictures on Facebook." (Participant Emma)

\section{Discussions}


To capture the degree of individuals' negotiation between the host and home cultures, Berry (1997) developed an acculturation framework that includes assimilation, integration, separation and marginalisation as different acculturation strategies. Although Berry's framework was challenged for its lack of fluidity (Askegaard et al., 2005), existing literature still very much holds the view that acculturation outcomes influence consumption practices in the same way, without paying much attention to exploring how consumers' acculturation strategies may be dissimilar across diverse areas of consumption. Our findings challenge such assumptions by showing the inconsistency occurring between food and media consumption behaviour amongst British sojourners in China. By showing how British sojourners are capable of adopting different acculturation strategies in different consumption practices, we argue that sojourners' acculturation strategy is much more pragmatic and fluid, to assist their negotiation, shaped by the host culture community, the host state public policy, the attitudes of the host culture community towards members of outgroups and sojourners' interpersonal relationships with the host culture community (Bourhis et al., 1997).

As this study maps out British sojourners' consumption decisions in two different fields of practices, findings reveal a variety of consumption practices, reflecting sojourners' flexible and pragmatic cultural stance. Figure 1 illustrates the various acculturation strategies that British sojourners adopt in China in two different areas of consumption. In terms of food consumption, British sojourners display a much more integrative approach reflecting both home and host cultures by consuming a variety of food alternatives, alternating between British food, Western food, Chinese food, other East-Asian food and global fast food brands for different occasions. Most of them demonstrate elastic and negotiable attitudes towards food consumption. This may be due to the fact that China has such a strong and long history in food culture, whilst British culture is characterised by its openness to other culinary cultures, making British consumers very versatile in their diets (Warde et al., 1999; 
Cappellini et al., 2016). With less emphasis on the food culture, British sojourners can easily integrate into the host food culture. In particular, when there is an established social tie with a Chinese connection (e.g. spouse, partner, friends), the acculturation to the host country's food becomes even easier and faster.

When it comes to media consumption, they adopt different strategies for traditional media and social media. Most British sojourners adopt an assimilation strategy towards Chinese social media such as WeChat to keep in touch with different social groups for very pragmatic reasons. WeChat provides British sojourners with the convenience and comfort to communicate with their families back home and stay connected locally with friends, colleagues and acquaintances in China. In media consumption, they often undertake a separation strategy and refuse to go through news produced by the Chinese state-controlled media due to their lack of debate, information freedom and variety, which are contradictory to the British value of freedom of speech. Hence, they actively employ devices like VPN to keep themselves updated with the latest news from home sources. While British sojourners show a very willing attitude towards Chinese social media adoption, their traditional media choices remain very static.

Figure 1: British Sojourners' Diversified Acculturation Strategies for Different Consumptions

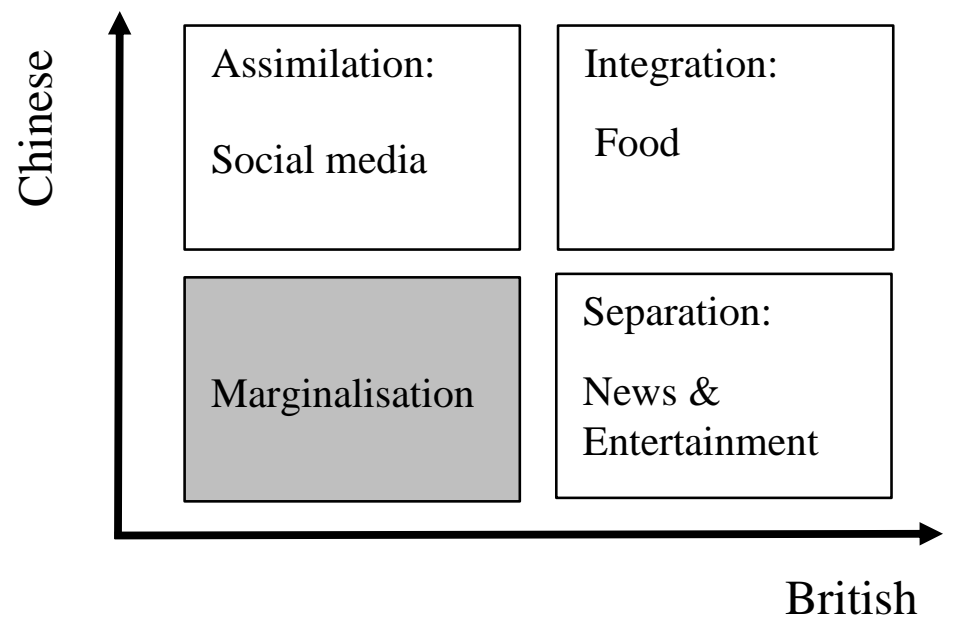




\section{Cultural Identity and Negotiation between Two Cultures}

Cultural identity refers to the extent to which people in a culture recognise and identify with a set of focal elements that set the culture apart from others (Clark, 1990). It emphasises a link between an individual and his/her historical and cultural heritage (He \& Wang, 2015). Due to China's rich cultural heritage and emphasis on collectivism, the influence of cultural identity on consumer behaviour will be more observable than that found in individualistic Western societies (Wang \& Lin, 2009). For Chinese consumers, food consumption carries a strong cultural imprint that will enhance one's cultural identity. As such, research shows that Chinese people sojourning to a foreign country will keep eating Chinese food to maintain their cultural heritage (He \& Wang, 2015; Yen et al., 2018) because a well-developed, strong sense of cultural identity provides meaning and symbolic value of one's belonging.

In contrast, our findings reveal British sojourners hold a more flexible and integrated attitude to food consumption by appreciating and accommodating Chinese food culture and practices, as well as keeping their home food culture in a continuous negotiation. Our findings confirm that the notion of cultural hybridity implies that sojourners' cultural identity is swifter and more fluid than immigrants' and undergoes a continuous and dynamic process of negotiation (Kraidy, 2002). As such, we have observed different acculturation strategies exercised by British sojourners in China, holding a different cultural stance on a different type of consumption choice for pragmatic reasons (Kraidy, 2002), which, we argue, reflect participants' cultural identities.

Whilst food is employed by British sojourners as a platform to sample, negotiate and make sense of the Chinese culture on a daily basis, news consumption is something that cannot be negotiated, as the Chinese alternatives challenge their British identity of freedom of speech and individual liberty. Findings are also very different to previous studies investigating 
Eastern immigrants to Western countries who tend to acculturate themselves via consuming the local media to fit in with the host culture (Raman \& Harwood, 2016), but heavily use food to help forge their ethnic identity (Cappellini \& Yen, 2013). Such consumption patterns highlight the importance of studying different fields of practice in discussing acculturation because identity fluidity is not only dynamic over time, but also active across different fields of consumption practice.

The findings have implications for brands, marketers and policymakers who want to influence sojourners from different cultural backgrounds by using a more complex acculturation model in their marketing strategies and campaign design. People with different home cultures living in a host culture tend to present very different acculturation approaches towards different fields of practice. They may present a highly integrated acculturation towards one product category whilst having a highly separated strategy towards another. Hence, selecting the sojourners as a target market is not universally feasible across different consumptions as the acculturation pattern of their host country product adoption can vary greatly.

\section{Limitations and Future Research}

The findings of this research are limited as they are derived from a small number of participants. The poor distribution in gender proportion in the sample also needs to be taken into consideration. It is possible that some of the acculturation patterns noted in this study are the results of participants' social or family roles, or may be due to their existing social ties, such as having a Chinese wife, girlfriend, etc. Hence, further research is necessary in terms of including a larger number of participants with good distribution in demographic profiles. It is also worth noticing that the current research only focuses on food and media consumption. Replications of the study are necessary to include more culture-related consumptions, such as 
education, social activities, ethnic consumptions, etc. Moreover, selecting a sample containing British sojourners living in China with a wide difference in the time scope may also influence the findings, as each individual's stage of the family cycle may change together with the change of cultural identity in their acculturation process.

Despite these limitations, this research shows different acculturation strategies that British sojourners adopt in an Eastern country, contributing to the scant literature on Western consumers' acculturation and consumption behaviour when living in the East. This study may shed light for future research by using longitudinal research overseeing each individual's acculturation process during a certain period of time. Further studies could also look at people from other Western countries, such as the U.S., France and Germany, which all have a comparatively large number of people living in Eastern countries. Further quantitative studies may also help to establish a more comprehensive conceptual and constructional framework to argue the validity of the research. 


\section{References:}

Askegaard, S., Arnould, E.J. \& Kjeldgaard, D. (2005). Postassimilationist ethnic consumer research: Qualifications and extensions, Journal of Consumer Research, 32(1),160170.

Bardhi, F., Eckhardt, G. and Arnould, E. J. (2012). Liquid Relationship to Possessions, Journal of Consumer Research, 39 (3), 510-29.

Bardhi, F., Ostberg, J. \& Bengtsson, A. (2010). Negotiating cultural boundaries: Food, travel and consumer identities, Consumption Markets \& Culture, 13(2), 133-157.

Bengtsson, A., Bardhi, F. \& Venkatraman, M. (2010). How global brands travel with consumers: an examination of the relationship between brand consistency and meaning across national boundaries, International Marketing Review, 27(5), 519-540.

Berry, J.W. (1997). Immigration, acculturation, and adaptation, Applied Psychology: An International Review, 46(1), 5-68.

Berry, J.W. (2008). Globalisation and acculturation, International Journal of Intercultural Relations, 32(4), 328-336.

Bourhis, R. Y., Moïse, C., Perreault, S. \& Senéca, S. (1997). Toward an interactive acculturation model: A social psychological approach, International Journal of Psychology, 32 (6), 369-386.

Cappellini, B. \& Yen, D.A. (2013). Little Emperors in the UK: Acculturation and food over time, Journal of Business Research, 66 (8), 968-974.

Cappellini, B. \& Yen, D.A. (2016). A space of one's own: spatial and identity liminality in an online community of mothers, Journal of Marketing Management, 32 (13-14), 12601283. 
Cappellini, B., Parsons, E. \& Harman, V. (2016). Right taste wrong place: local food cultures, (dis)identification and the formation of classed identity, Sociology, 50(6), 1089-1105.

Cappellini, B., Hosany, S., Yen, D.A. \& Yu, Q. (2019). Away from home: how young Chinese consumers travel with global brands, Journal of Retailing and Consumer Services. 46 (January), 87-94.

Clark, T. (1990). International marketing and national character: a review and proposal for an integrative theory, Journal of Marketing, 54 (4), 66-79.

Cleveland, M. \& Laroche, M. (2007). Acculturation to the global consumer culture: scale development and research paradigm, Journal of Business Research, 60(3), 249-259.

Cleveland, M., Papadopoulos, N. \& Laroche, M. (2011). Identity, demographics, and consumer behaviours: International market segmentation across product categories, International Marketing Review, 28(3), 244-266.

Dalisay, F. (2012). Media use and acculturation of new immigrants in the United States, Communication Research Reports, 29(2), 148-160.

Edirisingha, P. A., Ferguson, S. \& Aitken, R. (2015). From 'me' to 'we': negotiating new family identity through meal consumption in Asian cultures, Qualitative Market Research: An International Journal, 18 (4), 477-49.

Evans, E. (2011). British History: Victorians, available at: http://www.bbc.co.uk/history/british/victorians/overview_victorians_01.shtml (accessed online on 19/02/2019)

Gudykunst, W.B. (2004). Bridging differences: Effective intergroup communication, Sage, California. 
Harris, Beth. \& Zucker, S. (2018). “A brief history of Western culture,” in Smarthistory, available at : https://smarthistory.org/a-brief-history-of-western-culture/ (accessed online on 27/04/2019)

Hassid, J. (2008). Controlling the Chinese media, An uncertain business, Asian Survey, 48, (3), 414-430.

He, J. \& Wang, C. (2015). The impact of cultural identity and consumer ethnocentrism on buying domestic vs. import brands: An empirical study in China, Journal of Business Research, 68 (6), 1225-1233.

Hottola, P. (2004). Culture confusion: Intercultural adaptation in tourism, Annals of Tourism Research, 31(2), 447-466.

Khan, M. (1992). Communication patterns of sojourners in the process of acculturation, The Journal of Development Communication, 3(2), 65-73.

Kim, Y.Y. (2001). Becoming Intercultural: An Integrative Theory of Communication and Cross-Cultural Adaptation, Sage, Thousand Oaks, CA.

Kraidy, M.M. (2002). Hybridity in cultural globalisation, Communication Theory, 3 (1), 316339.

Li, A. (2017). Ninety-eight foreigners living in China and Shanghai is the most favourable city of choice, available at:

http://www.bjnews.com.cn/graphic/2017/09/12/457764.html (accessed online 19/02/2019)

Lu, P. (2013), How to apply a Chinese Green Card by foreigners. People’s Daily (Overseas Edition), available at: http://paper.people.com.cn/rmrbhwb/html/201310/25/content_1314787.html (accessed online 27/01/2016)

Ma, G. (2015). Food, eating behaviour, and culture in Chinese society, Journal of Ethnic Foods, 2(4), 195-199. 
McCracken, G. (1988). The long interview, Sage, London.

Oswald, L. (1999). Culture swapping: consumption and the ethnogenesis of middle-class Haitian immigrants, Journal of Consumer Research, 25(2), 303-18.

Penaloza, L. (1994). Atravesando Fronteras/border crossings: a critical ethnographic exploration of the consumer acculturation of Mexican immigrants, Journal of Consumer Research, 21 (1), 32-54.

Raman, P. \& Harwood, J. (2016). Media usage and acculturation: Asian Indian professionals in Silicon Valley, Journal of Intercultural Communication Research, 45(5), 355-373.

Ren, C. (2011). Wei Yuan and the Chinese Totalistic Iconoclasm: The Demise of Confucianism in Matter and in Form. Honors Project, 48, available at: https://digitalcommons.iwu.edu/history_honproj/48 (accessed 14/12/2018)

Ryder, G.A., Alden, L. E. \& Paulus, L. (2000). Is acculturation unidimensional or bidimensional? A head-to-head comparison in the prediction of personality, selfidentity, and adjustment, Journal of personality and social psychology, 79(1), 49-65.

Silverman, D. (2013). Doing Qualitative Research, Sage, London.

Spiggle, S. (1994). Analysis and interpretation of qualitative data in consumer research, Journal of Consumer Research, 21(3), 491-504.

Stockmann, D. \& Gallagher, M.E. (2011). Remote Control: How the Media Sustain Authoritarian Rule in China, Comparative Political Studies, 44(4), 436-467.Sui, C.P. (1952). The sojourner, American Journal of Sociology, 58(1), 34-44.

Thompson, C. J. \& Tambyah, S. K. (1999). Trying to Be Cosmopolitan, Journal of Consumer Research, 26 (December), 214-41.

Ulver, S. \& Ostberg, J. (2014). Moving up, down or sideways? Exploring consumer experience of identity and status incongruence, European Journal of Marketing, 48 $(5 / 6), 833-853$. 
Wamwara-Mbugua, W.L., Cornwell, B.T. \& Boller, G. (2008). Triple acculturation: the role of African Americans in the consumer acculturation of Kenyan immigrants, Journal of Business Research, 61(4), 83-90.

Wang, C. L., Bristol, T., Mowen, J. \& Chakraborty, G. (2000). Alternative modes of selfconstrual: Dimensions of connectedness-separateness and advertising appeals to the cultural and gender-specific self, Journal of Consumer Psychology, 9 (2), 107-115.

Wang, C. L. \& Lin, X. (2009). Migration of Chinese consumption values: Traditions, modernisation, and cultural renaissance, Journal of Business Ethics, 88 (3), 399 409.

Wang, C. L. \& Mowen, J. C. (1997). The separateness-connectedness self-schema: Scale development \& application to message construction, Psychology \& Marketing, 14 (2), 185-207.

Warde, A., Martens, L. \& Olsen, W. (1999). Consumption and the problem of variety: Cultural omnivorousness, social distinction and dining out, Sociology, 33(1), 105127.

Ward, C. \& Rana-Deuba, A. (2000). Home and host culture influences on sojourner adjustment, International Journal of Intercultural Relations, 24(3), 291-306.

White, L. \& Yanamandram, V. (2004). Why customers stay: reasons and consequences of inertia in financial services, Managing Service Quality: An International Journal, 14(2/3), 183-194.

Wilkin, H.A., Katz, V.S. \& Ball-Rokeach, S.J. (2009). The role of family interaction in new immigrant Latino's civic engagement, Journal of Communication, 59(2), 387-406.

Willis, K. \& Yeoh, B. (2002). Gendering transnational communities: a comparison of Singaporean and British migrants in China, Geoforum, 33 (4), 553-565. 
Woo, H.J. \& Dominick, J.R. (2001). Daytime television talk shows: cultivation effect among U.S and international students, Journal of Broadcasting and Electronic Media, 45(4), $598-614$.

Wu, D. \& Cheung, S. (2002). Introduction: The Globalisation of Chinese Food and Cuisine: Markers and Breakers of Cultural Barriers, in Cheung, S. and Wu, D. (Eds.), The Globalisation of Chinese Food, Routledge, London, pp. 1-18.

Xin, X. (2010). The impact of 'citizen journalism' on Chinese media and society, Journalism Practice, 4(3), 333-344.

Yang, C., Huaiting, W., Zhu, M., Brian, G. \& Southwell, M. (2004). Tuning in to fit it? Acculturation and media use among Chinese students in the United States, Asian Journal of Communication, 14(1), 81-94.

Yen, D.A., Cappellini, B., Wang, C.L. \& Nguyen, B. (2018). Food consumption when travelling abroad: Young Chinese sojourners' food consumption in the UK, Appetite, 121, 198-206.

Yu, Q., Foroudi, P. \& Gupta, S. (2018). Far apart yet close by: Social media and acculturation among international students in the UK, Technological Forecast and Social Change, DOI: https://doi.org/10.1016/j.techfore.2018.09.026

Zhao, R. (2012).《中华饮食文化--“中华诵·经典诵读行动”之文化常识系列》, Zhonghua Publisher, Beijing. 
Table 1: Respondents' profile

\begin{tabular}{|c|c|c|c|c|c|c|c|c|}
\hline No. & $\begin{array}{l}\text { Pseudo } \\
\text { Names }\end{array}$ & Age & Gender & $\begin{array}{l}\text { Marital } \\
\text { status }\end{array}$ & Career & Location & $\begin{array}{l}\text { Strong } \\
\text { Chinese } \\
\text { ties }\end{array}$ & $\begin{array}{l}\text { Duration } \\
\text { of stay } \\
\text { in China }\end{array}$ \\
\hline 1 & Emma & 20 & Female & Single & Student & Zhejiang & No & 1 year \\
\hline 2 & Colin & 22 & Male & Single & Student & $\begin{array}{l}\text { Different } \\
\text { places }\end{array}$ & No & 4 months \\
\hline 3 & Paul & 20 & Male & Single & Student & Zhejiang & $\begin{array}{l}\text { Yes, } \\
\text { Chinese } \\
\text { girl- } \\
\text { friend }\end{array}$ & 1 year \\
\hline 4 & Peter & 25 & Male & Single & Student & Zhejiang & No & $\begin{array}{l}12 \\
\text { months }\end{array}$ \\
\hline 5 & Charlie & 22 & Male & Single & Entrepreneur & Jiangsu & No & 8 months \\
\hline 6 & Oscar & 35 & Male & $\begin{array}{l}\text { Married } \\
\text { with } \\
\text { kids }\end{array}$ & Head Teacher & Jiangsu & No & $\begin{array}{l}1 \text { year } \\
\text { and } 1 \\
\text { month }\end{array}$ \\
\hline 7 & George & 32 & Male & $\begin{array}{l}\text { Married } \\
\text { with } \\
\text { kids }\end{array}$ & Media & Zhejiang & No & $\begin{array}{l}5 \text { years } \\
\text { and } 6 \\
\text { months }\end{array}$ \\
\hline 8 & Tim & 34 & Male & $\begin{array}{l}\text { Married } \\
\text { with a } \\
\text { kid }\end{array}$ & Self-employed & Zhejiang & $\begin{array}{l}\text { Yes, } \\
\text { Chinese } \\
\text { wife }\end{array}$ & $\begin{array}{l}3 \text { years } \\
\text { and } 6 \\
\text { months }\end{array}$ \\
\hline 9 & Wilson & 32 & Male & Engaged & Education & Zhejiang & $\begin{array}{l}\text { Yes, } \\
\text { Chinese } \\
\text { fiancée }\end{array}$ & 7 years \\
\hline 10 & Arnold & 28 & Male & Single & Student & Zhejiang & $\mathrm{No}$ & 2 years \\
\hline 11 & Andy & 32 & Male & Engaged & Education & Zhejiang & No & 3 years \\
\hline 12 & Jake & 30 & Male & Engaged & Self-employed & Zhejiang & $\begin{array}{l}\text { Yes, } \\
\text { Chinese } \\
\text { fiancée }\end{array}$ & 7 years \\
\hline 13 & Tom & 28 & Male & Single & Student & Zhejiang & No & 6 years \\
\hline 14 & Edward & 42 & Male & Single & $\mathrm{R} \& \mathrm{D}$ & Shanghai & $\begin{array}{l}\text { Yes, } \\
\text { Chinese } \\
\text { girl- } \\
\text { friend }\end{array}$ & 4 years \\
\hline 15 & Ben & 48 & Male & Single & Education & Zhejiang & No & 4 years \\
\hline 16 & Ted & 46 & Male & Single & Education & Zhejiang & No & 5 years \\
\hline 17 & Dylon & 51 & Male & Engaged & Manufacturing & Zhejiang & $\begin{array}{l}\text { Yes, } \\
\text { Chinese } \\
\text { fiancée }\end{array}$ & 8 years \\
\hline 18 & Chris & 53 & Male & $\begin{array}{l}\text { Married } \\
\text { with } \\
\text { kids }\end{array}$ & Trade & Shanghai & $\begin{array}{l}\text { Yes, } \\
\text { Chinese } \\
\text { wife }\end{array}$ & 22years \\
\hline
\end{tabular}


Table 2: Food consumption in China.

\begin{tabular}{|l|l|l|}
\hline & Ordinary Meals & Extraordinary Meals \\
\hline $\begin{array}{l}\text { Cooking Western } \\
\text { food at home }\end{array}$ & $\begin{array}{l}\text { Home-made Western (including } \\
\text { British) food is regularly } \\
\text { consumed for safety, familiarity, } \\
\text { reassurance and maintenance. }\end{array}$ & $\begin{array}{l}\text { Not so suitable for such an } \\
\text { occasion. }\end{array}$ \\
\hline $\begin{array}{l}\text { Western bars and } \\
\text { restaurants }\end{array}$ & $\begin{array}{l}\text { Sometimes consumed for } \\
\text { comfort and convenience, as the } \\
\text { menus are in English. }\end{array}$ & $\begin{array}{l}\text { Often consumed with } \\
\text { Westerners from other } \\
\text { countries, or to celebrate a } \\
\text { special family occasion. }\end{array}$ \\
\hline Chinese fast food & $\begin{array}{l}\text { Consumed regularly for } \\
\text { convenience, not always for } \\
\text { taste. }\end{array}$ & $\begin{array}{l}\text { Not applicable, as better options } \\
\text { are available. }\end{array}$ \\
\hline Chinese restaurants & $\begin{array}{l}\text { Consumed regularly as they are } \\
\text { generally affordable and tasty. }\end{array}$ & $\begin{array}{l}\text { Consumed for socialising and } \\
\text { celebratory purpose, especially } \\
\text { with Chinese friends and family } \\
\text { members. }\end{array}$ \\
\hline Global food brands & $\begin{array}{l}\text { Consumed for convenience and } \\
\text { familiarity. }\end{array}$ & $\begin{array}{l}\text { Not really considered as an } \\
\text { appropriate option. }\end{array}$ \\
\hline
\end{tabular}

Table 3: Media consumption in China.

\begin{tabular}{|l|l|l|}
\hline & Chinese Media & Western Media \\
\hline News & $\begin{array}{l}\text { Limited consumption. Chinese } \\
\text { news media is consumed for } \\
\text { local news. }\end{array}$ & $\begin{array}{l}\text { Continuous and regular } \\
\text { consumption. }\end{array}$ \\
\hline $\begin{array}{l}\text { Entertainment } \\
\text { (including TV } \\
\text { programmes and } \\
\text { movies) }\end{array}$ & $\begin{array}{l}\text { Sporadic consumption for } \\
\text { entertainment value and to } \\
\text { improve their language. }\end{array}$ & $\begin{array}{l}\text { Regularly consumed for } \\
\text { comfort, familiarity and } \\
\text { entertainment value. }\end{array}$ \\
\hline Social Media & $\begin{array}{l}\text { Eagerly consumed on a daily } \\
\text { basis to make sense of the new } \\
\text { environment and create more } \\
\text { opportunities. }\end{array}$ & $\begin{array}{l}\text { Regularly consumed to stay } \\
\text { connected with family and } \\
\text { friends back home. }\end{array}$ \\
\hline
\end{tabular}


General sojourning experience

- How long have you been in China?

- What brought you to China in the first place?

- What made you stay for years?

- Do you plan to come back to Britain soon? When is it going to be? Why?

- What do you think about the place that you are living in China?

- Have you picked up some Chinese language? How acculturate are you? Would you give us an example?

Food consumption

- Could you please describe a typical day's experience in China, particularly in terms of food consumption? Breakfast, lunch and supper? During the weekends?

- What do you think about Chinese food? What have you tried? What's your favourite? What do you find it hard to accept?

- Do you cook British food in China?

Media consumption

- Do you watch Chinese TV or movies?

- Do you follow Chinese news channels?

- Do you watch British movies or TV programmes?

- Do you follow British news? Which channels?

- What is the social media that you are mostly using when you are in China? Why?

- Do you still keep in touch with your British family and friends back at home? By which means? 